\title{
Topographical organization of the pedunculopontine nucleus
}

\author{
Cristina Martinez-Gonzalez, J. Paul Bolam and Juan Mena-Segovia* \\ Medical Research Council Anatomical Neuropharmacology Unit, Department of Pharmacology, University of Oxford, Oxford, UK
}

Edited by:

Jose L. Lanciego, University of

Navarra, Spain

Reviewed by:

Micaela Morelli, University of Cagliari,

Italy

Marisela Morales, National Institute of

Neurological Disorders and Stroke,

USA

\section{*Correspondence:}

Juan Mena-Segovia, Medical Research Council Anatomical

Neuropharmacology Unit, Department of Pharmacology, University of Oxford, Mansfield Road, Oxford OX1 3TH, UK. e-mail: juan.mena-segovia@pharm. ox.ac.uk

\begin{abstract}
Neurons in the pedunculopontine nucleus (PPN) exhibit a wide heterogeneity in terms of their neurochemical nature, their discharge properties, and their connectivity. Such characteristics are reflected in their functional properties and the behaviors in which they are involved, ranging from motor to cognitive functions, and the regulation of brain states. A clue to understand this functional versatility arises from the internal organization of the PPN. Thus, two main areas of the PPN have been described, the rostral and the caudal, which display remarkable differences in terms of the distribution of neurons with similar phenotype and the projections that originate from them. Here we review these differences with the premise that in order to understand the function of the PPN it is necessary to understand its intricate connectivity. We support the case that the PPN should not be considered as a homogeneous structure and conclude that the differences between rostral and caudal PPN, along with their intrinsic connectivity, may underlie the basis of its complexity.
\end{abstract}

Keywords: pedunculopontine, brainstem, basal ganglia, reticular activating system, neuronal heterogeneity, synaptic organization, microcircuits, connectivity

\section{INTRODUCTION}

The pedunculopontine nucleus (PPN) is located in the upper brainstem and has an irregular shape delimited by the borders of its population of cholinergic neurons. The PPN has been conserved in evolution across species and is present in early mammals and amphibians (Marin et al., 1998; Grillner et al., 2008). Defined in humans in 1982 (Olszewski and Baxter, 1982), it is considered a part of the reticular activating system and, as a reticular structure, it has been argued that PPN has no clear boundaries. One of the main characteristics of neurons of the PPN is their long-range axonal projections, reaching numerous targets across the brain, from distant forebrain structures (Woolf and Butcher, 1986; Hallanger and Wainer, 1988a) to the spinal cord (Rye et al., 1988; Spann and Grofova, 1989). Although initially considered to function as a relay nucleus within ascending activating systems, increasing evidence on the neuronal heterogeneity of the PPN and its local synaptic organization, suggest that this high level of connectivity with functionally distinct neuronal systems underlies an integrative function rather than a role as a simple relay nucleus. An example of this heterogeneous connectivity is the way the PPN is integrated into basal ganglia circuits: distinct functional types of neurons in the PPN innervate basal ganglia and, in turn, basal ganglia projects back to PPN and innervate different neuronal populations. This remarkable interconnectivity has been the subject of previous reviews that have stressed that most structures of the basal ganglia project to, and receive inputs from, the PPN (Pahapill and Lozano, 2000; Mena-Segovia et al., 2004). In the present review we will discuss recent evidence on the heterogeneous distribution of neurochemical subtypes of neurons within the PPN and correlate this with data on their connectivity. We will make use of the large amount of information available that describe the anatomical relationship that the PPN maintains with the basal ganglia and that provide evidence of a topographical organization. We will also correlate such organization with the connectivity of the PPN with other neuronal systems to integrate a theory supporting functional domains in the PPN.

\section{NEUROCHEMICAL DIVERSITY}

It has now been widely agreed that the PPN is composed by a mixture of neurons of different sizes, of different neurochemical phenotype and with distinct connectivity. Cholinergic neurons represent a minority of the neurons in the PPN and are intermingled amongst a large number of GABAergic and glutamatergic neurons, which are heterogeneously distributed across its rostrocaudal axis (Mena-Segovia et al., 2009; Wang and Morales, 2009). A parasagittal view of the PPN illustrates the different distributions of the neuronal populations and therefore better represents the anatomical organization of the PPN. Using external landmarks such as the substantia nigra ( $\mathrm{SN}$ ) and the superior cerebellar peduncle, which maintain a constant spatial relationship with the PPN across different medio-lateral levels, it is possible to follow the distribution of the cell types that compose the PPN. GABAergic neurons are more densely concentrated in the rostral PPN, compared to cholinergic and glutamatergic neurons. In the rat they are detectable from the rostral border of the PPN (limiting the caudal part of the $\mathrm{SN}$ ) and their density decreases dramatically at a level about 1.2-1.5 mm further caudal (Mena-Segovia et al., 2009; Figure 1). Such a drop in the density of GABAergic neurons coincides with a change in the cytoarchitecture and organization of cholinergic neurons: bipolar-shaped cholinergic neurons tend to be organized in a layer-like structure close to the SN, where GABAergic neurons are several times more abundant. Following the decline in the number of GABAergic neurons, rounded-shaped cholinergic neurons show a distinct configuration. Instead of lying in the layerlike arrangement, cholinergic neurons show an apparently random distribution and an increased number of processes. The change in density of cholinergic neurons, however, is not as marked as that of the GABAergic neurons or the glutamatergic neurons. In contrast to the rostral PPN, the caudal part of the nucleus has a larger proportion of glutamatergic neurons (Wang and Morales, 2009). Until now, no other neurochemical cell types have been identified 


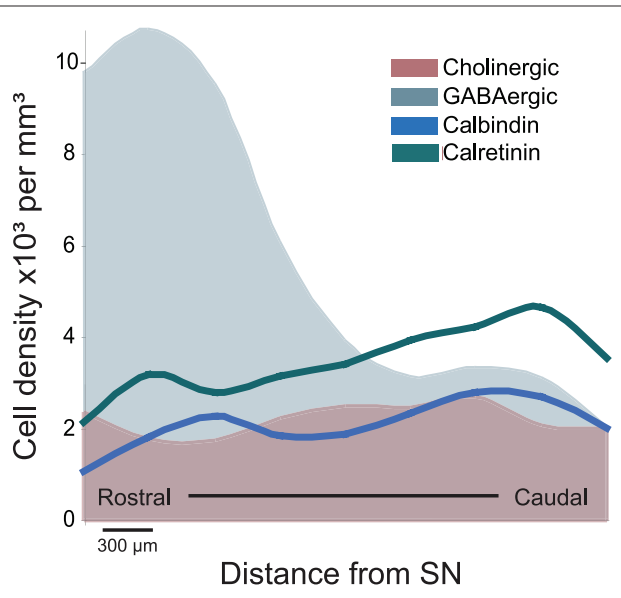

FIGURE 1 | Schematic representation of the distribution of distinct neuronal populations in the PPN. GABAergic neurons are highly concentrated in the rostral PPN, whereas cholinergic, glutamatergic (not shown), calbindin- and calretinin-expressing neurons are more abundant in the caudal PPN. The PPN was divided into $300 \mu \mathrm{m}$ segments and cell density was evaluated throughout its rostro-caudal extent (Martinez-Gonzalez et al., 2009, Mena-Segovia et al., 2009). The difference in the rostro-caudal distribution of GABAergic neurons correlates with the differences in cytoarchitecture of the cholinergic neurons traditionally used to identify PPN regions (i.e., pars dissipata and pars compacta). As shown in this figure, the rostral PPN is an area of high neuronal density. SN, substantia nigra.

although differences have been observed within each neuronal type in relation to the co-expression of other neurochemical markers and their firing properties.

In different regions of the brain including hippocampus (Acsady et al., 1993; Somogyi and Klausberger, 2005), cortex (Staiger et al., 2004), and basal ganglia (Parent et al., 1996), neurons that express calcium-binding proteins have been shown to have distinct functional properties despite the fact that they may use the same transmitter. They have thus proved to be useful markers to distinguish sub-populations of neurons. Calcium-binding proteins have also been reported to be expressed by neurons in the PPN in monkeys (Cote and Parent, 1992; Fortin and Parent, 1999) and rats (Dun et al., 1995), and indeed, calbindin and calretinin are expressed by a similar number of neurons to that of cholinergic neurons in the rat PPN (Martinez-Gonzalez et al., 2009). Although they are rarely expressed in cholinergic neurons, they are commonly expressed by GABAergic and glutamatergic neurons suggesting functional subtypes of GABAergic and glutamatergic neurons.

Significant differences have been observed also in terms of the in vivo firing properties of $\mathrm{PPN}$ neurons. Cholinergic neurons show two types of firing patterns: slow-firing cholinergic neurons that are associated to the cortical upstate during slow oscillations, and fast-firing cholinergic neurons that are correlated to the cortical downstate during slow oscillations (Mena-Segovia et al., 2008). No neurochemical markers of these subtypes have been identified. Neurons that have been identified as non-cholinergic and have been assigned as putative glutamatergic neurons because they give rise to asymmetric synaptic contacts in their targets, also show two main subtypes: fast-firing neurons that are associated with the cortical slow oscillations (Mena-Segovia et al., 2008), and quiescent (or very slow firing) neurons whose firing is independent of the cortical activity (Ros et al., 2010). These putative glutamatergic neurons have a different axonal trajectory and pattern of innervation from those of cholinergic neurons, although some targets are shared by both types (notably, the basal ganglia). Other neurons that have not been characterized in terms of their neurochemical nature include tonic firing neurons and irregular firing neurons; it is likely that at least one of these subtypes are GABAergic (Ros et al., 2010). The correlation between neurochemical subtypes and electrophysiological properties recorded in in vitro experiments is more limited. Three types of neurons have been described on the basis of their membrane properties (A-current type, low-threshold spikes type and mixed A-current plus LTS type; Leonard and Llinas, 1994; Takakusaki et al., 1997; Saitoh et al., 2003), although this classification does not seem to be related to their neurochemical nature (and therefore not to their synaptic targets). The different membrane properties, however, are likely to underlie some of the functional differences within each cell subtype.

In summary, each main neuronal type in the PPN is composed of at least two subtypes; the PPN is thus a highly heterogeneous structure at the cellular, molecular, and electrophysiological levels. The different neuronal types are heterogeneously distributed in the PPN, perhaps delineating functional territories (rostral and caudal) determined by a greater density of GABAergic axons arising from the rostral PPN in contrast to a greater density of cholinergic and glutamatergic axons arising from the caudal PPN, thus producing contrasting effects on their target structures.

\section{INTERNAL STRUCTURE AND CONNECTIVITY: THE CASE FOR SUBDIVISIONS OF THE PPN}

The notion that the PPN is not homogeneous in terms of its cellular organization is not recent; the PPN was originally divided in pars dissipata (rostral) and pars compacta (caudal) on the basis of the density of cholinergic neurons (Olszewski and Baxter, 1982), which were believed to be the most representative, if not the only, neuronal type in the PPN (Rye et al., 1987). Other subdivisions included rostral, middle, and caudal thirds, and the inclusion of an area referred to as the midbrain extrapyramidal area (MEA) which receives a dense innervation from the basal ganglia but lies outside the cholinergic borders of the PPN (Steininger et al., 1992). While all of these subdivisions are based on identifiable characteristics in the anatomy of the PPN, it is perhaps the rostral and caudal division that is the most appropriate since it is based on the distribution of all known cell types rather than only the cholinergic neurons. Indeed, GABAergic neurons provide a unique distribution that correlates with the cholinergic pars dissipata and pars compacta subdivisions (Mena-Segovia et al., 2009). The rostro-caudal division is also the basis for many anatomical studies describing afferents and efferents to and from the PPN, as discussed in the following sections, but essentially does not rely on cell density (as the terms dissipata and compacta denote).

The idea of two functionally distinct regions of the PPN is supported by the distribution of its cell types defined on the basis of neurochemistry and the connectivity of the PPN with other neuronal systems. Thus, two neurochemically distinct projections arising from rostral and caudal PPN diverge, innervating distinct 
structures, but also converge in others. This functional dichotomy seems to be locally regulated, as suggested by the evidence of axonal collaterals of PPN neurons. Thus, a local synaptic network has been identified after tracing the axons of individually labeled neurons (Mena-Segovia et al., 2008; Ros et al., 2010). Both cholinergic and non-cholinergic neurons contribute to this connectivity, although the number of axonal varicosities was found to be greater in cholinergic neurons. Interestingly, a large proportion of PPN projection neurons have axons that travel within the PPN in a rostro-caudal direction, providing local innervation that synaptically links the rostral and the caudal portions. This evidence of a local network of heterogeneous neurochemical nature supports the role of the PPN as an integrator between its input and output systems.

\section{EFFERENT CONNECTIVITY}

Neurons of the PPN give rise to long axons that innervate several targets. The longest axons arise from cholinergic neurons and give rise to as many as five or six collaterals that innervate the basal ganglia, thalamus, tectum, and lower brainstem, among other regions (Mena-Segovia et al., 2008). The axons of non-cholinergic neurons are more restricted in terms of length and number of collaterals (typically two; Ros et al., 2010). Single-cell labeling experiments, have demonstrated that both cholinergic and non-cholinergic neurons project preferentially to the basal ganglia and that several divisions of the basal ganglia are innervated. Tracer studies have also produced extensive data on the connections of neurons in the PPN (Table 1).

\section{BASAL GANGLIA}

Tracer experiments have shown that the STN receives input from the PPN in the cat (Nomura et al., 1980; Edley and Graybiel, 1983), rat (Saper and Loewy, 1982; Hammond et al., 1983), and monkey (Carpenter et al., 1981; Lavoie and Parent, 1994). More recently, tractography studies have confirmed these findings in humans (Muthusamy et al., 2007). In the monkey and rat, the neurons that project to the STN are located in the caudal PPN (Carpenter et al., 1981; Martinez-Gonzalez et al., 2009; Kita and Kita, 2010). Such projections have been identified to include cholinergic, GABAergic, and glutamatergic components (Bevan and Bolam, 1995).

The entopeduncular nucleus (EP, in rat and cat, equivalent to the internal segment of the globus pallidus or GPi in the monkey) receives input from the PPN (Saper and Loewy, 1982; Jackson and Crossman, 1983; Woolf and Butcher, 1986; Shink et al., 1997), and these projections have an excitatory influence on EP neurons in the rat and cat (Gonya-Magee and Anderson, 1983; Scarnati et al., 1988). A species-specific difference seems to exist regarding the density of these projections, since they have been reported to be larger in the monkey than in the cat (Edley and Graybiel, 1983). In the monkey, tracer injections in the GPi give rise to a large number of retrogradely labeled PPN neurons in the rostral PPN, around $40 \%$ of which are cholinergic. In contrast, a restricted GPe injection produced a smaller number of labeled neurons in the PPN (Charara and Parent, 1994). This difference was confirmed by anterograde labeling, Phaseolus vulgaris leucoagglutinin injections in the PPN give rise to a much higher density of anterogradely labeled fibers in the GPi than in the GPe (Lavoie and Parent, 1994).
The $\mathrm{SN}$ pars compacta $(\mathrm{SNc})$ and pars reticulata $(\mathrm{SNr})$ are interconnected with the PPN (Saper and Loewy, 1982; Woolf and Butcher, 1986). In the rat and monkey, SNc dopaminergic neurons receive direct glutamatergic and cholinergic input from PPN neurons (Sugimoto and Hattori, 1984; Clarke et al., 1987; Scarnati et al., 1987; Gould et al., 1989; Bolam et al., 1991; Futami et al., 1995; Oakman et al., 1995; Charara et al., 1996). These projections emit collaterals that innervate the medial reticular formation in the cat (Nakamura et al., 1989). Furthermore, the activation of the PPN can elicit an excitatory effect on SN neurons in the rat (Scarnati et al., 1984, 1987), evoking monosynaptic glutamatergic and cholinergic excitatory postsynaptic potentials in dopamine neurons (Futami et al., 1995) and non-dopamine neurons (Rohrbacher et al., 2000). In the monkey, the neurons that project to the $\mathrm{SN}$ are concentrated in the rostral PPN and about $25 \%$ of these are cholinergic. However, very few projecting neurons are located in the caudal PPN (Lavoie and Parent, 1994). In the rat, cholinergic and non-cholinergic neurons that arborize within the $\mathrm{SNc}$ are preferentially located in the rostral PPN (Takakusaki et al., 1996). These projections are mostly ipsilateral (Oakman et al., 1995, 1999).

The ventral tegmental area (VTA) also receives substantial cholinergic innervation from the PPN in the rat and monkey (Sugimoto and Hattori, 1984; Oakman et al., 1995; Charara et al., 1996; Geisler and Zahm, 2005). In monkeys, retrograde tracing experiments have shown the existence of glutamatergic and GABAergic afferents from the PPN to the VTA (Charara et al., 1996). In the rat, neurons that send projections to the VTA are concentrated in the caudal PPN, project bilaterally and involve cholinergic (Sugimoto and Hattori, 1984; Oakman et al., 1995), GABAergic and glutamatergic axons (Mena-Segovia et al., 2005). In vitro, stimulation of cortical and PPN afferents to the VTA induce glutamatergic synaptic currents in VTA dopaminergic and non-dopaminergic neurons (Bonci and Malenka, 1999). More recently, it has been described that GABAergic and monosynaptic glutamatergic PPN inputs do not converge on the same VTA neurons (Good and Lupica, 2009). Nicotinic acetylcholine receptors ( $\mathrm{AAChR}$ ) can also modulate this excitatory synaptic transmission (Good and Lupica, 2009).

Last but not least, a direct projection from the PPN to the striatum (or caudate/putamen in primates) has been identified in the rat (Saper and Loewy, 1982) and in the monkey (Nakano et al., 1990).

\section{THALAMUS}

The thalamus is heavily innervated by the PPN in the rat (Saper and Loewy, 1982; Hallanger and Wainer, 1988a), cat and monkey (Parent et al., 1988), and a large proportion of this output is cholinergic (Sugimoto and Hattori, 1984; Sofroniew et al., 1985; Hallanger et al., 1987; Hallanger and Wainer, 1988a,b; Takakusaki et al., 1996; Oakman et al., 1999; Parent and Descarries, 2008). The projections are widespread, innervating several thalamic nuclei (Smith et al., 1988; Steriade et al., 1988; Kolmac and Mitrofanis, 1998), they are topographically organized in the cat (Steriade et al., 1988) and monkey (Lavoie and Parent, 1994), and arise from neurons that are predominantly located in the caudal PPN. In the cat and monkey, the majority of the thalamic nuclei receive less than $10 \%$ of their PPN innervation from the rostral PPN, with the exception of the mediodorsal thalamic nucleus, which receives up to $20 \%$ of its innervation from the rostral PPN (Steriade et al., 1988). 
Table 1 | Efferent connectivity of the pedunculopontine nucleus.

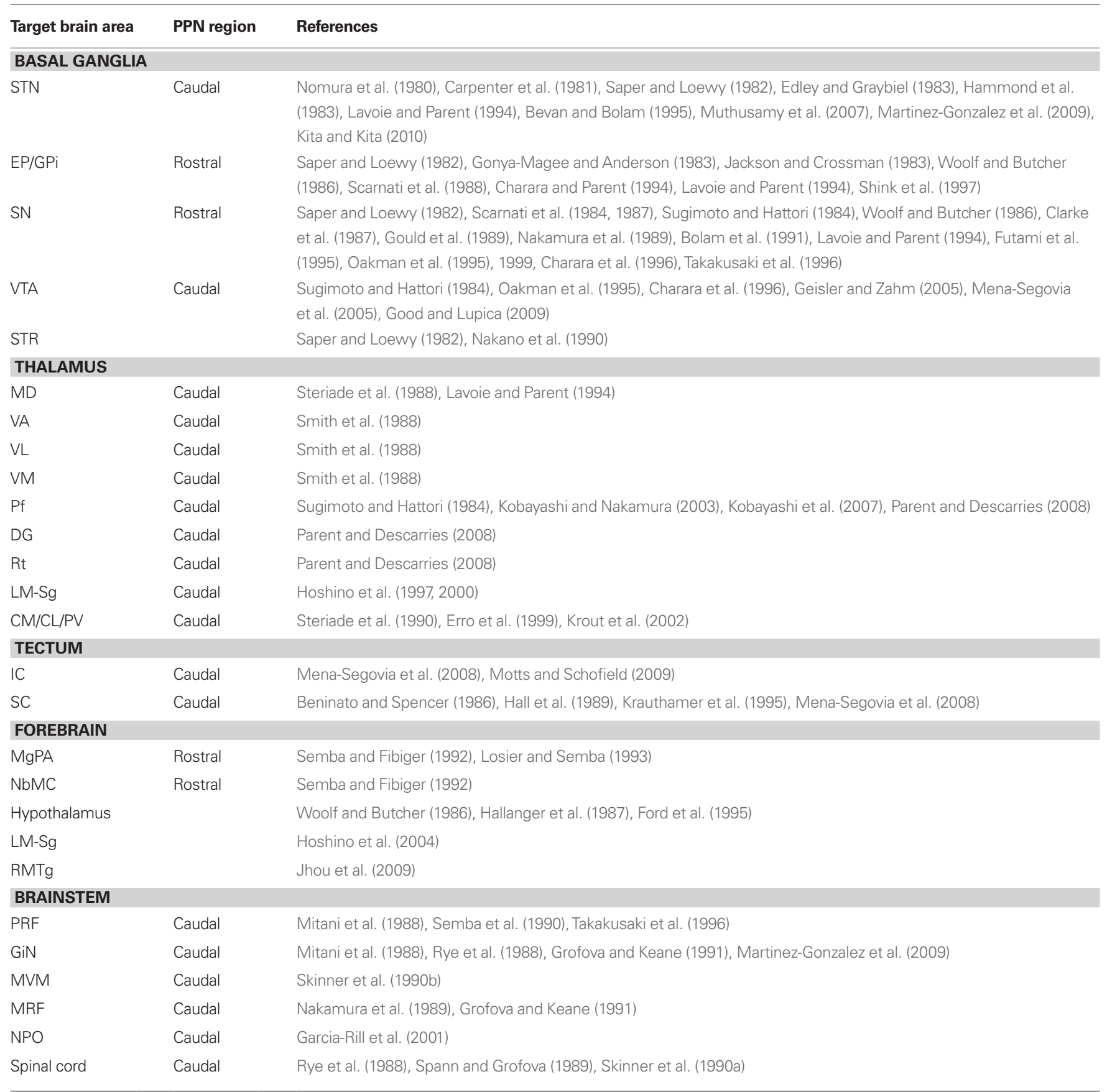

Abbreviations: STN, subthalamic nucleus; EP, entopeduncular nucleus; GPi, internal segment of the globus pallidus; SN, substantia nigra; VTA, ventral tegmental area; STR, striatum; MD, mediodorsal; VA, ventral anterior; VL, ventro-lateral; VM, ventro-medial; Pf, parafascicular; DG, dorsal geniculate; Rt, retocular thalamic; LM-Sg, lateralis medialis-suprageniculate; CM, centromedian; CL, centrolateral; PV, paraventricular; IC, inferior colliculus; SC, superior colliculus; MgPA, magnocellular preoptic area; NbMC, nucleus basalis magnocellularis; RMTg, mesopontine rostromedial tegmental nucleus; PRF, pontine reticular formation; GiN, gigantocellular nucleus; MVM, medioventral medulla; MRF, medial reticular formation; NPO, nucleus pontis oralis.

The thalamic input from the PPN is both cholinergic and noncholinergic (Smith et al., 1988; Steriade et al., 1988). Retrograde labeling from the mediodorsal thalamic nucleus produces prominent labeling of non-cholinergic neurons in both the ipsilateral and contralateral PPN in the cat (Smith et al., 1988). The ventroanterior and the ventro-lateral thalamic nuclei receive between 50 and $75 \%$ of their cholinergic afferents from the central-caudal PPN, whereas the ventro-medial thalamic nucleus receives its cholinergic input mainly from the caudal PPN and the laterodorsal tegmental nucleus (Smith et al., 1988). In the rat, the parafasicular nucleus (Pf) receives inputs from the caudal PPN (Sugimoto and Hattori, 1984). The cholinergic innervation to the Pf has a higher density than the 
innervation to the dosolateral geniculate and reticular thalamic nuclei (Parent and Descarries, 2008). Individual Pf neurons receive convergent synaptic inputs from the PPN and the SC (Kobayashi and Nakamura, 2003). In turn, Pf neurons that receive inputs from the PPN project to striatum (Erro et al., 1999), linking monosynaptically PPN axons to thalamostriatal neurons (Kobayashi et al., 2007). Cholinergic neurons that project to the thalamus send collaterals to the basal forebrain (Losier and Semba, 1993), the pontine reticular formation (Semba et al., 1990), the superior and inferior colliculi, and the basal ganglia (Mena-Segovia et al., 2008). In the cat, glutamatergic and GABAergic neurons of the lateralis medialissuprageniculate nuclear complex (LM-Sg) receive cholinergic input from the PPN (Hoshino et al., 1997, 2000). Other thalamic nuclei receive a more heterogeneous mixture of cholinergic and noncholinergic PPN afferents, such as the centrolateral, centromedial, and paraventricular thalamic nuclei in the rat (Erro et al., 1999; Krout et al., 2002).

\section{OTHER ASCENDING PROJECTIONS}

Individual cholinergic neurons of the PPN project to the superior and inferior colliculi in the rat (Mena-Segovia et al., 2008). The large majority of the cholinergic inputs to the inferior colliculus arise from the ipsilateral PPN and to a less extent, from the LTD. These projections arise from cholinergic neurons that are located in the caudal PPN and include a subpopulation that project to both the ipsilateral and contralateral inferior colliculus in the guinea pig (Motts and Schofield, 2009). The superior colliculus receives cholinergic and non-cholinergic innervation from the PPN in the rat and cat (Beninato and Spencer, 1986; Hall et al., 1989). These afferents arise mainly from the caudal PPN (Beninato and Spencer, 1986). PPN neurons projecting to the superior colliculus, as identified by antidromic stimulation, are segregated into two groups: those that are sensitive and those that are insensitive to physiological sensory stimuli (Krauthamer et al., 1995). A small group of neurons located in the rostral PPN have collaterals that innervate the superior colliculus and the LM-Sg in the cat (Hoshino et al., 2004). In the rat, other ascending targets include the mesopontine rostromedial tegmental nucleus (RMTg; Jhou et al., 2009).

In the forebrain, the magnocellular preoptic area (MgPA) and the nucleus basalis magnocellularis receive afferents from the PPN (Semba et al., 1988; Losier and Semba, 1993). The posterior lateral hypothalamus receives cholinergic input from PPN neurons that are scattered throughout the rostro-caudal axis, and GABAergic innervation from neurons that are concentrated in the rostral PPN; the neurochemical nature of the majority of the projection neurons was not identified (Ford et al., 1995).

\section{BRAINSTEM AND OTHER DESCENDING PROJECTIONS}

Neurons in the PPN make a dense innervation on structures in the lower brainstem, pons, medulla, and spinal cord. The descending projections arise from collaterals of ascending axons, as seen in cholinergic (Mena-Segovia et al., 2008) and non-cholinergic neurons (Martinez-Gonzalez et al., 2009), or from non-cholinergic neurons with single descending axons (Ros et al., 2010). Both cholinergic and non-cholinergic neurons innervate the pontine reticular formation in the rat (Semba et al., 1990; Takakusaki et al.,
1996) and the cat (Mitani et al., 1988). Thus, PPN has been shown to project to the gigantocellular nucleus $(\mathrm{GiN})$ in rats and cats (Mitani et al., 1988; Rye et al., 1988; Grofova and Keane, 1991; Martinez-Gonzalez et al., 2009), the medioventral medulla (Skinner et al., 1990b), rostral ventro-lateral medulla (Yasui et al., 1990), medial reticular formation, medulla oblongata (Nakamura et al., 1989; Grofova and Keane, 1991), and the spinal cord in rats (Rye et al., 1988; Spann and Grofova, 1989; Skinner et al., 1990a). The majority of the PPN projecting neurons to the spinal cord are non-cholinergic (Skinner et al., 1990a). These descending PPN projections are considered to be directly involved in locomotion since the stimulation of neurons in the caudal PPN leads to a prolonged activation of neurons in the nucleus reticularis pontis oralis and changes in the flexor and extensor nerves in decorticated cats (Garcia-Rill et al., 2001).

In summary, the ascending projections from the rostral PPN preferentially innervate the EP/GPi, SN and the lateral hypothalamus in the rat, cat, and monkey. In contrast, ascending projections from the caudal PPN innervate the thalamus, STN, VTA, SC, and IC.

\section{AFFERENT CONNECTIVITY}

Although the information available on the afferent innervation to the PPN is not as abundant and detailed as it is with regards to its efferents, it is clear that the PPN receives a heterogeneous modulation arising from functionally diverse areas of the brain. Thus, neurons in the PPN receive afferents from structures that include the cortex, thalamus, hypothalamus, pons, cerebellum, medulla, spinal cord, and the basal ganglia (Saper and Loewy, 1982; Semba and Fibiger, 1992; Table 2).

The PPN receives a direct input from the cerebral cortex arising from distinct frontal lobe areas involved in motor control in the monkey. These convergent inputs seem to target the dorsal and caudal PPN areas (Matsumura et al., 2000). In the rat, these afferents have also been demonstrated, although they seem to be less abundant (Semba and Fibiger, 1992). They arise also from the medial prefrontal cortex (Sesack et al., 1989). In addition, cholinergic PPN neurons receive afferents from the primary auditory cortex in guinea pigs (Schofield and Motts, 2009).

\section{BASAL GANGLIA}

The PPN receives a direct input from the STN in the rat (Jackson and Crossman, 1981; Kita and Kitai, 1987), the cat and the monkey (Nauta and Cole, 1978). In addition to the anatomical evidence, electrophysiological experiments in the rat have shown that this input is excitatory and it targets neurons in the PPN (Granata and Kitai, 1989). Furthermore, the STN can modulate PPN activity indirectly through the $\mathrm{SNr}$; this pathway has an inhibitory effect on PPN neurons (Hammond et al., 1983; Florio et al., 2007).

Tracer studies show that the EP sends projections that innervate PPN neurons in the rat (Semba and Fibiger, 1992) and in the monkey (Shink et al., 1997). In the latter, the GPi afferents preferentially target NADPH diaphorase-negative neurons in the rostral PPN, establishing symmetric synapses with proximal dendrites. GP afferents to the PPN arise from the caudal GP, in contrast to the rostral GP that projects to the STN (Moriizumi and Hattori, 1992). GPi axons that innervate PPN neurons arise from type I neurons that are abundant in the center of the GPi (Parent et al., 2001), 
Table 2 |Afferent connectivity of the pedunculopontine nucleus.

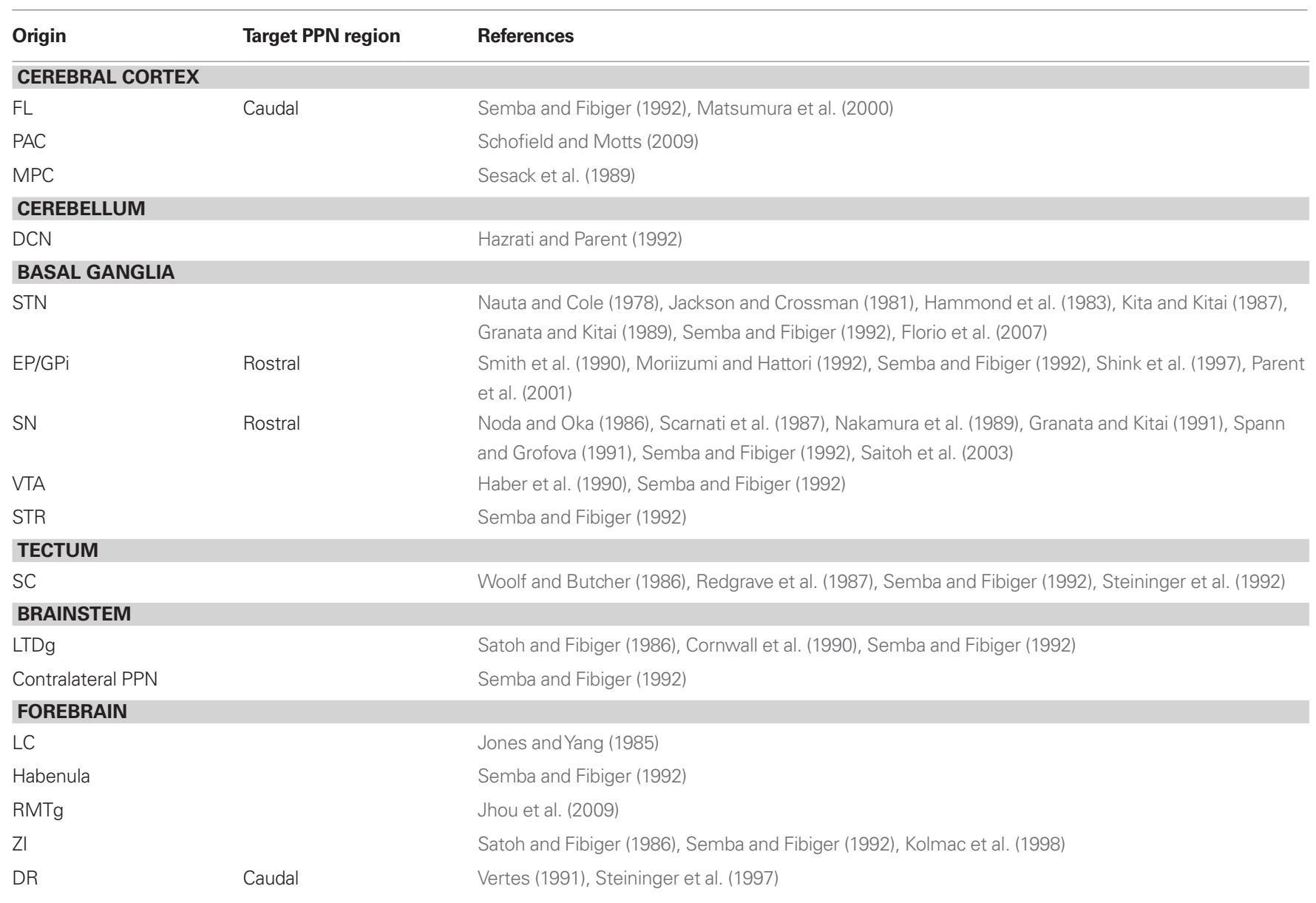

Abbreviations: FL, frontal lobe; PAC, primary auditory cortex; MPC, medial prefrontal cortex; DCN, deep cerebellar nuclei; STN, subthalamic nucleus; EP, entopeduncular nucleus; GPi, internal segment of the globus pallidus; SN, substantia nigra; VTA, ventral tegmental area; STR, striatum; SC, superior colliculi; LTDg, laterodorsal tegmental nucleus; PPN, pedunculopontine nucleus; LC, locus ceruleus; RMTg, mesopontine rostromedial tegmental nucleus; ZI, zona incerta; DR, dorsal raphé.

although some authors differ on this, finding retrogradely labeled neurons in the whole GP after retrograde tracer injection in the rat STN (Smith et al., 1990). This is particularly relevant because the PPN is involved into a circuit that involves the STN and GP, one of the principal outflows of the basal ganglia.

The PPN also receives afferents from the $\mathrm{SN}$ in the rat and cat (Nakamura et al., 1989; Spann and Grofova, 1991; Semba and Fibiger, 1992), and this input is inhibitory (Noda and Oka, 1984; Scarnati et al., 1987; Granata and Kitai, 1991) and mediated by GABA (Saitoh et al., 2003). It is not clear yet which PPN neurons are the targets of these afferents, but electron microscopy (EM) studies have shown that nigral afferents to the PPN establish synaptic contacts preferentially with non-cholinergic neurons located in the rostral PPN (Spann and Grofova, 1991; Grofova and Zhou, 1998). Some of these neurons are glutamatergic, and a lower proportion are cholinergic (Grofova and Zhou, 1998).

Other basal ganglia projections to the PPN include the ventral striatum in monkey (Haber et al., 1990) and the VTA in rats (Semba and Fibiger, 1992). Indeed, PPN neurons receive a dopaminergic innvervation presumably arising from the mesencephalon in the monkey (Rolland et al., 2009).

\section{OTHER AFFERENT SYSTEMS}

The PPN receives afferents from the habenula (Semba and Fibiger, 1992) and the zona incerta (Semba and Fibiger, 1992; Kolmac et al., 1998), the deep cerebellar nuclei (Hazrati and Parent, 1992), the mesopontine RMTg (Jhou et al., 2009) and the superior and inferior colliculi in the rat (Woolf and Butcher, 1986; Redgrave et al., 1987; Semba and Fibiger, 1992; Steininger et al., 1992).

In the brainstem, tracer studies in the rat have shown that the rostral and caudal portions of the dorsal raphé send projections that innervate the PPN (Vertes, 1991), where they preferentially target non-cholinergic neurons in the caudal PPN (Steininger et al., 1997). The locus coeruleus (Jones and Yang, 1985) and the laterodorsal tegmental nucleus also innervate the PPN (Satoh and Fibiger, 1986; Cornwall et al., 1990; Semba and Fibiger, 1992). Furthermore, the PPN receives an input from the contralateral PPN (Semba and Fibiger, 1992).

In summary, the PPN receives afferents from the basal ganglia, cortex, thalamus, cerebellum, forebrain, spinal cord, pons, and the contralateral PPN. The rostral PPN receives inhibitory input from the $\mathrm{SN}$ and the EP/GPi. The caudal PPN receives inputs from the dorsal raphé and the motor cortex. 


\section{FUNCTIONAL IMPLICATIONS OF TOPOGRAPHY}

The data arising from the connectivity studies show that a significant number of structures have a selective relationship with distinct regions within the PPN. This is clearly evident from the analysis of retrograde and anterograde tracing studies showing the distribution of PPN projecting neurons, although less clear with regards to the distribution of the PPN afferents. Nevertheless, in the case of PPN inputs, two important neuronal systems, the basal ganglia and the cortex, seem to contact neurons in distinct regions of the PPN. Thus, the GABAergic output neurons of the basal ganglia, arising in the $\mathrm{SNr}$ and $\mathrm{EP} / \mathrm{GPi}$, mainly contact neurons located in the rostral PPN. In contrast, neurons in the cortex and the dorsal raphé preferentially innervate neurons in the caudal PPN. In terms of its efferents, the rostral PPN projects to the SNr, SNc, $\mathrm{GPi}$, and the hypothalamus. In contrast, the caudal PPN projects to the STN, the VTA, the thalamus, and the superior and inferior colliculi (Figure 2).

The differences in connectivity suggest that there is a functional reciprocity in different areas of the PPN with regards to its inputs and outputs. These differences reveal that, (1) the rostral PPN, which contains a significantly larger number of GABAergic neurons, is interconnected with the structures that provide the GABAergic output from the basal ganglia, therefore suggesting a close functional relationship with basal ganglia operations; and (2) the caudal PPN, which contains a larger number of cholinergic and glutamatergic neurons, receives information from cortex and dorsal raphé, and projects to targets in the thalamus and colliculi, suggesting a close relationship with the modulation of brain states mediated through thalamocortical systems. Moreover, it is also the caudal PPN that projects to the STN and to the brainstem locomotor regions involved in gait and posture and the modulation of the muscular tone across different brain states.

Behavioral studies following restricted lesions or selective manipulations in the rostral and caudal PPN have shown functional differences between these two PPN areas that correlate with the functional domains defined by the neurochemical distribution and connectivity (Inglis et al., 2001; Alderson et al., 2006, 2008; Andero et al., 2007). Such functional differences have relevance for deep brain stimulation (DBS) therapy in the PPN in Parkinson's disease patients (Starr et al., 1998; Pahapill and Lozano, 2000; Nandi et al.,

\section{REFERENCES}

Acsady, L., Halasy, K., and Freund, T. F. (1993). Calretinin is present in non-pyramidal cells of the rat hippocampus - III. Their inputs from the median raphe and medial septal nuclei. Neuroscience 52, 829-841.

Alderson, H. L., Latimer, M. P., and Winn, P. (2006). Intravenous selfadministration of nicotine is altered by lesions of the posterior, but not anterior, pedunculopontine tegmental nucleus. Eur. J. Neurosci. 23, 2169-2175.

Alderson, H. L., Latimer, M. P., and Winn, P. (2008). A functional dissociation of the anterior and posterior pedunculopontine tegmental nucleus: excitotoxic lesions have differential effects on locomotion and the response to nicotine. Brain Struct. Funct. 213, 247-253.

Andero, R., Torras-Garcia, M., QuirozPadilla, M. F., Costa-Miserachs, D., and Coll-Andreu, M. (2007). Electrical stimulation of the pedunculopontine tegmental nucleus in freely moving awake rats: time- and site-specific effects on two-way active avoidance conditioning. Neurobiol. Learn. Mem. 87, 510-521.

Benabid, A. L. (2003). Deep brain stimulation for Parkinson's disease. Curr. Opin. Neurobiol. 13, 696-706.

Beninato, M., and Spencer, R. F. (1986). A cholinergic projection to the rat superior colliculus demonstrated by retrograde transport of horseradish

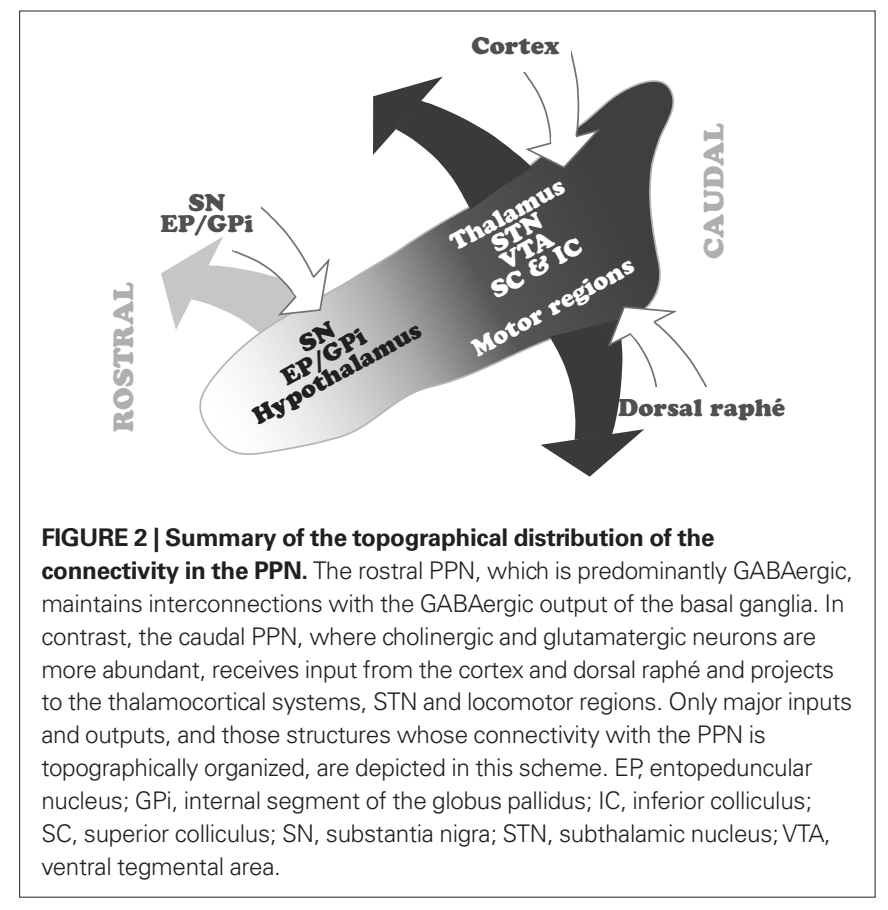

2002; Benabid, 2003; Jenkinson et al., 2005; Stefani et al., 2007). As is evident from the cell types and their efferents, it is most likely that the stimulation of an electrode situated in the rostral PPN will have very different effects to an electrode situated in the caudal PPN.

\section{CONCLUSION}

The PPN is subdivided in two functionally distinct regions: the rostral portion, which is predominantly inhibitory and interconnected with the basal ganglia, and the caudal portion, which is predominantly excitatory and closely related to arousal and motor systems. These two functionally distinct areas are locally regulated and synaptically linked by the local axon collaterals of cholinergic and non-cholinergic neurons. The extent of the interaction between these two regions remains to be determined, but will help to elucidate the common mechanism by which PPN neurons seem to participate in a wide range of behavioral functions.

peroxidase and choline acetyltransferase immunohistochemistry. $J$. Comp. Neurol. 253, 525-538.

Bevan, M. D., and Bolam, J. P. (1995) Cholinergic, GABAergic, and glutamate-enriched inputs from the mesopontine tegmentum to the subthalamic nucleus in the rat. J. Neurosci. 15, 7105-7120.

Bolam, J. P., Francis, C. M., and Henderson, Z. (1991). Cholinergic input to dopaminergic neurons in the substantia nigra: a double immunocytochemical study. Neuroscience 41, 483-494.

Bonci, A., and Malenka, R. C. (1999). Properties and plasticity of excitatory synapses on dopaminergic and GABAergic cells in the ventral tegmental area. J. Neurosci. 19, 3723-3730.

Carpenter, M. B., Carleton, S. C., Keller, J. T., and Conte, P. (1981). Connections of the subthalamic nucleus in the monkey. Brain Res. 224, 1-29.

Charara, A., and Parent, A. (1994). Brainstem dopaminergic, cholinergic and serotoninergic afferents to the pallidum in the squirrel monkey. Brain Res. 640, 155-170.

Charara, A., Smith, Y., and Parent, A. (1996). Glutamatergic inputs from the pedunculopontine nucleus to midbrain dopaminergic neurons in primates: Phaseolus vulgarisleucoagglutinin anterograde labeling combined with postembedding glutamate and GABA 
immunohistochemistry. J. Comp. Neurol. 364, 254-266.

Clarke, P. B., Hommer, D. W., Pert, A., and Skirboll, L. R. (1987). Innervation of substantia nigra neurons by cholinergic afferents from pedunculopontine nucleus in the rat: neuroanatomical and electrophysiological evidence. Neuroscience 23, 1011-1019.

Cornwall, J., Cooper, J. D., and Phillipson, O. T. (1990). Afferent and efferent connections of the laterodorsal tegmental nucleus in the rat. Brain Res. Bull. 25, 271-284.

Cote, P. Y., and Parent, A. (1992). Calbindin D-28k and choline acetyltransferase are expressed by different neuronal populations in pedunculopontine nucleus but not in nucleus basalis in squirrel monkeys. Brain Res. 593, 245-252.

Dun, N. J., Dun, S. L., Hwang, L. L., and Forstermann, U. (1995). Infrequent co-existence of nitric oxide synthase and parvalbumin, calbindin and calretinin immunoreactivity in rat pontine neurons. Neurosci. Lett. 191, 165-168.

Edley, S. M., and Graybiel, A. M. (1983). The afferent and efferent connections of the feline nucleus tegmenti pedunculopontinus, pars compacta. J. Comp. Neurol. 217, 187-215.

Erro, E., Lanciego, J. L., and GimenezAmaya, J. M. (1999). Relationships between thalamostriatal neurons and pedunculopontine projections to the thalamus: a neuroanatomical tracttracing study in the rat. Exp. Brain Res. 127, 62-170.

Florio, T., Scarnati, E., Confalone, G., Minchella, D., Galati, S., Stanzione, P., Stefani, A., and Mazzone, P. (2007). High-frequency stimulation of the subthalamic nucleus modulates the activity of pedunculopontine neurons through direct activation of excitatory fibres as well as through indirect activation of inhibitory pallidal fibres in the rat. Eur. J. Neurosci. 25, 1174-1186.

Ford, B., Holmes, C. J., Mainville, L., and Jones, B. E. (1995). GABAergic neurons in the rat pontomesencephalic tegmentum: codistribution with cholinergic and other tegmental neurons projecting to the posterior lateral hypothalamus. J. Comp. Neurol. 363, 177-196.

Fortin, M., and Parent, A. (1999). Calretinin-immunoreactive neurons in primate pedunculopontine and laterodorsal tegmental nuclei. Neuroscience 88, 535-547.

Futami, T., Takakusaki, K., and Kitai, S. T. (1995). Glutamatergic and cholinergic inputs from the pedunculopontine tegmental nucleus to dopamine neurons in the substantia nigra pars compacta. Neurosci. Res. 21, 331-342.
Garcia-Rill, E., Skinner, R. D., Miyazato, H., and Homma, Y. (2001). Pedunculopontine stimulation induces prolonged activation of pontine reticular neurons. Neuroscience 104, 455-465.

Geisler, S., and Zahm, D. S. (2005). Afferents of the ventral tegmental area in the rat-anatomical substratum for integrative functions. J. Comp. Neurol. 490, 270-294.

Gonya-Magee, T., and Anderson, M. E. (1983). An electrophysiological characterization of projections from the pedunculopontine area to entopeduncular nucleus and globus pallidus in the cat. Exp. Brain Res. 49 , 269-279.

Good, C. H., and Lupica, C. R. (2009). Properties of distinct ventral tegmental area synapses activated via pedunculopontine or ventral tegmental area stimulation in vitro. J. Physiol. $587(\mathrm{Pt}$ 6), 1233-1247.

Gould, E., Woolf, N. J., and Butcher, L. L. (1989). Cholinergic projections to the substantia nigra from the pedunculopontine and laterodorsal tegmental nuclei. Neuroscience 28, 611-623.

Granata, A. R., and Kitai, S. T. (1989). Intracellular analysis of excitatory subthalamic inputs to the pedunculopontine neurons. Brain Res. 488, 57-72.

Granata, A. R., and Kitai, S. T. (1991). Inhibitory substantia nigra inputs to the pedunculopontine neurons. Exp. Brain Res. 86, 459-466.

Grillner, S., Wallen, P., Saitoh, K., Kozlov, A., and Robertson, B. (2008). Neural bases of goal-directed locomotion in vertebrates - an overview. Brain Res. Rev. 57, 2-12.

Grofova, I., and Keane, S. (1991). Descending brainstem projections of the pedunculopontine tegmental nucleus in the rat. Anat. Embryol. 184, 275-290.

Grofova, I., and Zhou, M. (1998). Nigral innervation of cholinergic and glutamatergic cells in the rat mesopontine tegmentum: light and electron microscopic anterograde tracing and immunohistochemical studies. J. Comp. Neurol. 395, 359-379.

Haber, S. N., Lynd, E., Klein, C., and Groenewegen, H. J. (1990). Topographic organization of the ventral striatal efferent projections in the rhesus monkey: an anterograde tracing study. J. Comp. Neurol. 293, 282-298.

Hall, W.C., Fitzpatrick, D., Klatt, L. L., and Raczkowski, D. (1989). Cholinergic innervation of the superior colliculus in the cat. J. Comp. Neurol. 287, 495-514.

Hallanger, A. E., Levey, A. I., Lee, H. J., Rye, D. B., and Wainer, B. H. (1987). The origins of cholinergic and other subcortical afferents to the thalamus in the rat. J. Comp. Neurol. 262, 105-124.

Hallanger, A. E., and Wainer, B. H. (1988a). Ascending projections from the pedunculopontine tegmental nucleus and the adjacent mesopontine tegmentum in the rat. J. Comp. Neurol. 274, 483-515.

Hallanger, A. E., and Wainer, B. H. (1988b). Ultrastructure of ChATimmunoreactive synaptic terminals in the thalamic reticular nucleus of the rat. J. Comp. Neurol. 278, 486-497.

Hammond, C., Rouzaire-Dubois, B., Feger, J., Jackson, A., and Crossman, A. R. (1983). Anatomical and electrophysiological studies on the reciprocal projections between the subthalamic nucleus and nucleus tegmenti pedunculopontinus in the rat. Neuroscience 9, 41-52.

Hazrati, L. N., and Parent, A. (1992). Projection from the deep cerebellar nuclei to the pedunculopontine nucleus in the squirrel monkey. Brain Res. 585, 267-271.

Hoshino, K., Hicks, T. P., Meguro, R., Hirano, S., Kase, M., and Norita, M. (1997). Cholinergic innervation of the lateralis medialis-suprageniculate nuclear complex (LM-Sg) of the cat's thalamus: a double labeling immunohistochemical study. Brain Res. 747, 151-155.

Hoshino, K., Katoh, Y. Y., Bai, W., Kaiya, T., and Norita, M. (2000). Distribution of terminals from pedunculopontine tegmental nucleus and synaptic organization in lateralis medialis-suprageniculate nucleus of cat's thalamus: anterograde tracing, immunohistochemical studies, and quantitative analysis. Vis. Neurosci. 17, 893-904.

Hoshino, K., Nagy, A., Eordegh, G., Benedek, G., and Norita, M. (2004). Two types of neuron are found within the PPT, a small percentage of which project to both the LM-SG and SC. Exp. Brain Res. 155, 421-426.

Inglis, W. L., Olmstead, M. C., and Robbins, T. W. (2001). Selective deficits in attentional performance on the 5-choice serial reaction time task following pedunculopontine tegmental nucleus lesions. Behav. Brain Res. 123, 117-131.

Jackson, A., and Crossman, A. R. (1981). Subthalamic projection to nucleus tegmenti pedunculopontinus in the rat. Neurosci. Lett. 22, 17-22.

Jackson, A., and Crossman, A. R. (1983). Nucleus tegmenti pedunculopontinus: efferent connections with special reference to the basal ganglia, studied in the rat by anterograde and retrograde transport of horseradish peroxidase. Neuroscience 10, 725-765. Jenkinson, N., Nandi, D., Aziz, T. Z., and Stein, J. F. (2005). Pedunculopontine nucleus: a new target for deep brain stimulation for akinesia. Neuroreport 16, 1875-1876.

Jhou, T. C., Geisler, S., Marinelli, M., Degarmo, B. A., and Zahm, D. S. (2009). The mesopontine rostromedial tegmental nucleus: a structure targeted by the lateral habenula that projects to the ventral tegmental area of Tsai and substantia nigra compacta. J. Comp. Neurol. 513, 66-596.

Jones, B. E., and Yang, T. Z. (1985). The efferent projections from the reticular formation and the locus coeruleus studied by anterograde and retrograde axonal transport in the rat. J. Comp. Neurol. 242, 56-92.

Kita, H., and Kitai, S. T. (1987). Efferent projections of the subthalamic nucleus in the rat: light and electron microscopic analysis with the PHA-L method. J. Comp. Neurol. 260, 435-452.

Kita, T., and Kita, H. (2010). Cholinergic and non-cholinergic mesopontine tegmental neurons projecting to the subthalamic nucleus in the rat. Eur. J. Neurosci. 33, 433-443.

Kobayashi, K., Hoshino, K., Homma, S., Takagi, S., and Norita, M. (2007). A possible monosynaptic pathway links the pedunculopontine tegmental nucleus to thalamostriatal neurons in the hooded rat. Arch. Histol. Cytol. 70, 207-214.

Kobayashi, S., and Nakamura, Y. (2003). Synaptic organization of the rat parafascicular nucleus, with special reference to its afferents from the superior colliculus and the pedunculopontine tegmental nucleus. Brain Res. 980, 80-91.

Kolmac, C. I., and Mitrofanis, J. (1998). Patterns of brainstem projection to the thalamic reticular nucleus. J. Comp. Neurol. 396, 531-543.

Kolmac, C. I., Power, B. D., and Mitrofanis, J. (1998). Patterns of connections between zona incerta and brainstem in rats. J. Comp. Neurol. 396, 544-555.

Krauthamer, G. M., Grunwerg, B. S., and Krein, H. (1995). Putative cholinergic neurons of the pedunculopontine tegmental nucleus projecting to the superior colliculus consist of sensory responsive and unresponsive populations which are functionally distinct from other mesopontine neurons. Neuroscience 69, 507-517.

Krout, K. E., Belzer, R. E., and Loewy, A. D. (2002). Brainstem projections to midline and intralaminar thalamic nuclei of the rat. J. Comp. Neurol. $448,53-101$.

Lavoie, B., and Parent, A. (1994). Pedunculopontine nucleus in the squirrel monkey: projections to the basal ganglia as revealed by 
anterograde tract-tracing methods. J. Comp. Neurol. 344, 210-231.

Leonard, C. S., and Llinas, R. (1994). Serotonergic and cholinergic inhibition of mesopontine cholinergic neurons controlling REM sleep: an in vitro electrophysiological study. Neuroscience 59, 309-330.

Losier, B. J., and Semba, K. (1993). Dual projections of single cholinergic and aminergic brainstem neurons to the thalamus and basal forebrain in the rat. Brain Res. 604, 41-52.

Marin, O., Smeets, W. J., and Gonzalez, A. (1998). Evolution of the basal ganglia in tetrapods: a new perspective based on recent studies in amphibians. Trends Neurosci. 21, 487-494.

Martinez-Gonzalez, C., Micklem, B. R., Bolam, J. P., and Mena-Segovia, J. (2009). Neurons containing calciumbinding proteins are topographically organized in the pedunculopontine nucleus. Program No. 845.17. 2009 Neuroscience Meeting Planner. Chicago, IL: Society for Neuroscience, 2009. Online.

Matsumura, M., Nambu, A., Yamaji, Y., Watanabe, K., Imai, H., Inase, M., Tokuno, H., and Takada, M. (2000). Organization of somatic motor inputs from the frontal lobe to the pedunculopontine tegmental nucleus in the macaque monkey. Neuroscience 98 , 97-110.

Mena-Segovia, J., Bolam, J. P., and Magill, P.J. (2004). Pedunculopontine nucleus and basal ganglia: distant relatives or part of the same family? Trends Neurosci. 27, 585-588.

Mena-Segovia, J., Micklem, B. R., NairRoberts, R. G., Ungless, M. A., and Bolam, J.P. (2009). GABAergic neuron distribution in the pedunculopontine nucleus defines functional subterritories. J. Comp. Neurol. 515, 397-408.

Mena-Segovia, J., Ross, H. M., Magill, P. J., and Bolam, J. P. (2005). "The pedunculopontine nucleus: towards a functional integration with the basal ganglia," in The Basal Ganglia VIII, eds J. P. Bolam, C. Ingham, and P. J. Magill (New York: Springer Science and Business Media), 533-544.

Mena-Segovia, J., Sims, H. M., Magill, P. J., and Bolam, J. P. (2008). Cholinergic brainstem neurons modulate cortical gamma activity during slow oscillations. J. Physiol. 586(Pt 12), 2947-2960.

Mitani, A., Ito, K., Hallanger, A.E., Wainer, B. H., Kataoka, K., and McCarley, R. W. (1988). Cholinergic projections from the laterodorsal and pedunculopontine tegmental nuclei to the pontine gigantocellular tegmental field in the cat. Brain Res. 451, 397-402.

Moriizumi, T., and Hattori, T. (1992). Separate neuronal populations of the rat globus pallidus projecting to the subthalamic nucleus, auditory cortex and pedunculopontine tegmental area. Neuroscience 46, 701-710.

Motts, S. D., and Schofield, B. R. (2009). Sources of cholinergic input to the inferior colliculus. Neuroscience 160, 103-114.

Muthusamy, K. A., Aravamuthan, B. R., Kringelbach, M. L., Jenkinson, N., Voets, N. L., Johansen-Berg, H., Stein, J. F., and Aziz, T. Z. (2007). Connectivity of the human pedunculopontine nucleus region and diffusion tensor imaging in surgical targeting. J. Neurosurg. 107, 814-820.

Nakamura, Y., Tokuno, H., Moriizumi, T., Kitao, Y., and Kudo, M. (1989). Monosynaptic nigral inputs to the pedunculopontine tegmental nucleus neurons which send their axons to the medial reticular formation in the medulla oblongata. An electron microscopic study in the cat. Neurosci. Lett. 103, 145-150.

Nakano, K., Hasegawa, Y., Tokushige, A., Nakagawa, S., Kayahara, T., and Mizuno, N. (1990). Topographical projections from the thalamus, subthalamic nucleus and pedunculopontine tegmental nucleus to the striatum in the Japanese monkey, Macaca fuscata. Brain Res. 537, 54-68.

Nandi, D., Liu, X., Winter, J. L., Aziz, T. Z., and Stein, J. F. (2002). Deep brain stimulation of the pedunculopontine region in the normal non-human primate. J. Clin. Neurosci. 9, 170-174.

Nauta, H. J., and Cole, M. (1978). Efferent projections of the subthalamic nucleus: an autoradiographic study in monkey and cat. J. Comp. Neurol. 180, 1-16.

Noda, T., and Oka, H. (1984). Nigral inputs to the pedunculopontine region: intracellular analysis. Brain Res. 322, 332-336.

Noda, T., and Oka, H. (1986). Distribution and morphology of tegmental neurons receiving nigral inhibitory inputs in the cat: an intracellular HRP study. J. Comp. Neurol. 244, 254-266.

Nomura, S., Mizuno, N., and Sugimoto, T. (1980). Direct projections from the pedunculopontine tegmental nucleus to the subthalamic nucleus in the cat. Brain Res. 196, 223-227.

Oakman, S. A., Faris, P. L., Cozzari, C., and Hartman, B. K. (1999). Characterization of the extent of pontomesencephalic cholinergic neurons' projections to the thalamus: comparison with projections to midbrain dopaminergic groups. Neuroscience 94, 29-547.

Oakman, S. A., Faris, P. L., Kerr, P. E., Cozzari, C., and Hartman, B. K. (1995). Distribution of pontomesencephalic cholinergic neurons projecting to substantia nigra differs significantly from those projecting to ventral tegmental area. J. Neurosci. 15,5859-5869.

Olszewski, J., and Baxter, D. (1982). Cytoarchitecture of the Human Brain Stem. Basel: S Karger AG.

Pahapill, P. A., and Lozano, A. M. (2000). The pedunculopontine nucleus and Parkinson's disease. Brain 123(Pt 9), 1767-1783.

Parent, A., Fortin, M., Cote, P. Y., and Cicchetti, F. (1996). Calcium-binding proteins in primate basal ganglia. Neurosci. Res. 25, 309-334.

Parent,A., Pare, D., Smith, Y., and Steriade, M. (1988). Basal forebrain cholinergic and noncholinergic projections to the thalamus and brainstem in cats and monkeys. J. Comp. Neurol. 277, 281-301.

Parent, M., and Descarries, L. (2008). Acetylcholine innervation of the adult rat thalamus: distribution and ultrastructural features in dorsolateral geniculate, parafascicular, and reticular thalamic nuclei. J. Comp. Neurol. 511, 678-691.

Parent, M., Levesque, M., and Parent, A. (2001). Two types of projection neurons in the internal pallidum of primates: single-axon tracing and three-dimensional reconstruction. $J$. Comp. Neurol. 439, 162-175.

Redgrave, P., Mitchell, I. J., and Dean, P. (1987). Descending projections from the superior colliculus in rat: a study using orthograde transport of wheatgerm-agglutinin conjugated horseradish peroxidase. Exp. Brain Res. 68, 147-167.

Rohrbacher, J., Ichinohe, N., and Kitai, S. T. (2000). Electrophysiological characteristics of substantia nigra neurons in organotypic cultures: spontaneous and evoked activities. Neuroscience 97 , 703-714.

Rolland, A. S., Tande, D., Herrero, M. T., Luquin, M. R., Vazquez-Claverie, M., Karachi, C., Hirsch, E. C., and Francois, C. (2009). Evidence for a dopaminergic innervation of the pedunculopontine nucleus in monkeys, and its drastic reduction after MPTP intoxication. J. Neurochem. 110, 1321-1329.

Ros, H., Magill, P. J., Moss, J., Bolam, J. P., and Mena-Segovia, J. (2010). Distinct types of non-cholinergic pedunculopontine neurons are differentially modulated during global brain states. Neuroscience 170, 78-91.

Rye, D. B., Lee, H. J., Saper, C. B., and Wainer, B. H. (1988). Medullary and spinal efferents of the pedunculopontine tegmental nucleus and adjacent mesopontine tegmentum in the rat. $J$. Comp. Neurol. 269, 315-341.

Rye,D.B.,Saper,C.B.,Lee,H.J., and Wainer, B. H. (1987). Pedunculopontine tegmental nucleus of the rat: cytoarchitecture, cytochemistry, and some extrapyramidal connections of the mesopontine tegmentum. J. Comp. Neurol. 259, 483-528.

Saitoh, K., Hattori, S., Song, W. J., Isa, T., and Takakusaki, K. (2003). Nigral GABAergic inhibition upon cholinergic neurons in the rat pedunculopontine tegmental nucleus. Eur. J. Neurosci. 18, 879-886.

Saper, C. B., and Loewy, A. D. (1982). Projections of the pedunculopontine tegmental nucleus in the rat: evidence for additional extrapyramidal circuitry. Brain Res. 252, 367-372.

Satoh, K., and Fibiger, H. C. (1986). Cholinergic neurons of the laterodorsal tegmental nucleus: efferent and afferent connections. J. Comp. Neurol. $253,277-302$.

Scarnati, E., Campana, E., and Pacitti, C. (1984). Pedunculopontine-evoked excitation of substantia nigra neurons in the rat. Brain Res. 304, 351-361.

Scarnati, E., Di Loreto, S., Proia, A., and Gallie, G. (1988). The functional role of the pedunculopontine nucleus in the regulation of the electrical activity of entopeduncular neurons in the rat. Arch. Ital. Biol. 126, 145-163.

Scarnati, E., Proia, A., Di Loreto, S., and Pacitti, C. (1987). The reciprocal electrophysiological influence between the nucleus tegmenti pedunculopontinus and the substantia nigra in normal and decorticated rats. Brain Res. 423, 116-124.

Schofield, B. R., and Motts, S. D. (2009). Projections from auditory cortex to cholinergic cells in the midbrain tegmentum of guinea pigs. Brain Res. Bull. 80, 163-170.

Semba, K., and Fibiger, H. C. (1992). Afferent connections of the laterodorsal and the pedunculopontine tegmental nuclei in the rat: a retro- and antero-grade transport and immunohistochemical study. J. Comp. Neurol. 323, 387-410.

Semba, K., Reiner, P. B., and Fibiger, H. C. (1990). Single cholinergic mesopontine tegmental neurons project to both the pontine reticular formation and the thalamus in the rat. Neuroscience $38,643-654$.

Semba, K., Reiner, P. B., McGeer, E. G., and Fibiger, H. C. (1988). Brainstem afferents to the magnocellular basal forebrain studied by axonal transport, immunohistochemistry, and electrophysiology in the rat. J. Comp. Neurol. 267, 433-453.

Sesack, S. R., Deutch, A.Y., Roth, R. H., and Bunney, B. S. (1989). Topographical organization of the efferent projections of the medial prefrontal cortex in the rat: an anterograde tract-tracing study 
with Phaseolus vulgaris leucoagglutinin. J. Comp. Neurol. 290, 213-242.

Shink, E., Sidibe, M., and Smith, Y. (1997). Efferent connections of the internal globus pallidus in the squirrel monkey: II. Topography and synaptic organization of pallidal efferents to the pedunculopontine nucleus. J. Comp. Neurol. 382, 348-363.

Skinner, R. D., Kinjo, N., Henderson, V., and Garcia-Rill, E. (1990a). Locomotor projections from the pedunculopontine nucleus to the spinal cord. Neuroreport 1, 183-186.

Skinner, R. D., Kinjo, N., Ishikawa, Y., Biedermann, J. A., and Garcia-Rill, E. (1990b). Locomotor projections from the pedunculopontine nucleus to the medioventral medulla. Neuroreport 1 , 207-210.

Smith, Y., Bolam, J. P., and Von Krosigk, M. (1990). Topographical and synaptic organization of the GABA-containing pallidosubthalamic projection in the rat. Eur. J. Neurosci. 2, 500-511.

Smith, Y., Pare, D., Deschenes, M., Parent, A., and Steriade, M. (1988). Cholinergic and non-cholinergic projections from the upper brainstem core to the visual thalamus in the cat. Exp. Brain Res. 70, 166-180.

Sofroniew, M. V., Priestley, J. V., Consolazione, A., Eckenstein, F., and Cuello, A. C. (1985). Cholinergic projections from the midbrain and pons to the thalamus in the rat, identified by combined retrograde tracing and choline acetyltransferase immunohistochemistry. Brain Res. 329, 213-223.

Somogyi, P., and Klausberger, T. (2005). Defined types of cortical interneurone structure space and spike timing in the hippocampus. J. Physiol. 562(Pt 1), 9-26.

Spann, B. M., and Grofova, I. (1989). Origin of ascending and spinal pathways from the nucleus tegmenti pedunculopontinus in the rat. J. Comp. Neurol. 283, 13-27.

Spann, B. M., and Grofova, I. (1991). Nigropedunculopontine projection in the rat: an anterograde tracing study with Phaseolus Vulgarisleucoagglutinin (PHA-L). J. Comp. Neurol. 311, 375-388.

Staiger, J. F., Masanneck, C., Schleicher, A., and Zuschratter, W. (2004). Calbindin-containing interneurons are a target for VIP-immunoreactive synapses in rat primary somatosensory cortex. J. Comp. Neurol. 468, 179-189.

Starr, P. A., Vitek, J. L., and Bakay, R. A. (1998). Deep brain stimulation for movement disorders. Neurosurg. Clin. N. Am. 9, 381-402.

Stefani, A., Lozano, A. M., Peppe, A., Stanzione, P., Galati, S., Tropepi, D., Pierantozzi, M., Brusa, L., Scarnati, E., and Mazzone, P. (2007). Bilateral deep brain stimulation of the pedunculopontine and subthalamic nuclei in severe Parkinson's disease. Brain 130, 1596-1607.

Steininger, T. L., Rye, D. B., and Wainer, B. H. (1992). Afferent projections to the cholinergic pedunculopontine tegmental nucleus and adjacent midbrain extrapyramidal area in the albino rat. I. Retrograde tracing studies. J. Comp. Neurol. 321, 515-543.

Steininger, T. L., Wainer, B. H., Blakely, R. D., and Rye, D. B. (1997). Serotonergic dorsal raphe nucleus projections to the cholinergic and noncholinergic neurons of the pedunculopontine tegmental region: a light and electron microscopic anterograde tracing and immunohistochemical study. J. Comp. Neurol. 382, 302-322.

Steriade, M., Datta, S., Pare, D., Oakson, G., and Curro Dossi, R. C. (1990). Neuronal activities in brain-stem cholinergic nuclei related to tonic activation processes in thalamocortical systems. J. Neurosci. 10, 2541-2559.

Steriade, M., Pare, D., Parent,A., and Smith, Y. (1988). Projections of cholinergic and non-cholinergic neurons of the brainstem core to relay and associational thalamic nuclei in the cat and macaque monkey. Neuroscience 25, 47-67.

Sugimoto, T., and Hattori, T. (1984) Organization and efferent projections of nucleus tegmenti pedunculopontinus pars compacta with special reference to its cholinergic aspects. Neuroscience 11, 931-946.

Takakusaki, K., Habaguchi, T., Nagaoka, T., and Sakamoto, T. (1997). Stimulus effects of pedunculopontine tegmental nucleus (PPTN) on hindlimb motoneurons in cats. Soc. Neurosci. Abstr. 23, 762.

Takakusaki, K., Shiroyama, T., Yamamoto, T., and Kitai, S. T. (1996). Cholinergic and noncholinergic tegmental pedunculopontine projection neurons in rats revealed by intracellular labeling. $J$. Comp. Neurol. 371, 345-361.

Vertes, R. P. (1991). A PHA-L analysis of ascending projections of the dorsal raphe nucleus in the rat. J. Comp. Neurol. 313, 643-668.

Wang, H. L., and Morales, M. (2009). Pedunculopontine and laterodorsal tegmental nuclei contain distinct populations of cholinergic, glutamatergic and GABAergic neurons in the rat. Eur. J. Neurosci. 29, 340-358.

Woolf, N. J., and Butcher, L. L. (1986). Cholinergic systems in the rat brain: III. Projections from the pontomesencephalic tegmentum to the thalamus, tectum, basal ganglia, and basal forebrain. Brain Res. Bull. 16, 603-637.

Yasui, Y., Cechetto, D. F., and Saper, C. B. (1990). Evidence for a cholinergic projection from the pedunculopontine tegmental nucleus to the rostral ventrolateral medulla in the rat. Brain Res. 517, 19-24.

Conflict of Interest Statement: The authors declare that the research was conducted in the absence of any commercial or financial relationships that could be construed as a potential conflict of interest.

Received: 31 December 2010; accepted: 21 March 2011; published online: 05 April 2011.

Citation: Martinez-Gonzalez C, Bolam JP and Mena-Segovia J (2011) Topographical organization of the pedunculopontine nucleus. Front. Neuroanat. 5:22. doi: 10.3389/fnana.2011.00022

Copyright $\odot 2011$ Martinez-Gonzalez, Bolam and Mena-Segovia. This is an openaccess article subject to a non-exclusive license between the authors and Frontiers Media SA, which permits use, distribution and reproduction in other forums, provided the original authors and source are credited and other Frontiers conditions are complied with. 